\title{
Development of fast release foaming vaginal tablets with clotrimazole. II. The influence of the environmental conditions on preparation and stability
}

\author{
Edit LÁSZLÓ, Ioan TOMUTA, Sorin E. LEUCUTA \\ Department of Pharmaceutical Technology and Biopharmacy, Faculty of Pharmacy, \\ "Iuliu Hatieganu" University of Medicine and Pharmacy Cluj-Napoca, Romania
}

\begin{abstract}
Objectives. The aim of this study was to evaluate the stability over time after storage under normal environmental thermo-hygrometric conditions of immediate release foaming vaginal tablets.

Material and methods. 15 formulation of foaming vaginal tablets prepared according with a Box-Bhenken experimental design were packaged in tightly sealed bottles with anhydrous sodium sulphate as desiccant and stored in normal thermo-hygrometric conditions (temperature of $25^{\circ} \mathrm{C}$, relative humidity $40-75 \%$ ). Immediate after preparation, after 1 and 3 months the tablets pharmaceutical characteristics were analysed and modification over time evaluated.

Outcomes. The formulation factors studied with experimental design have, in general, the same influence on tablets characteristics after 1 or 3 months storage as immediate after preparation After one month storage in normal thermohygrometric conditions, an increase of the tablets hardness and the foaming time was observed, and a decrease of the volume of the foam, the mass of carbon dioxide released by the foaming. These modifications are accentuated especially by an increased effervescent mixture ratio and not significantly influenced by the other formulation variables. The results obtained after three months storage show that the changes on the tablets characteristics become slower than in the first month. The tablets hardness reaches maximum values after one month, but also there are slower changes regarding the maximum volume of the foam, the resistance of the foam, or the mass of carbon dioxide released after foaming. Low modification was observed for the $\mathrm{pH}$ generated in the water, which has a fairly high stability over time, both at one month and after three months storage.
\end{abstract}

Conclusions. Foaming vaginal tablets stored in normal thermo-hygrometric conditions, suffer a sudden modification of their characteristics during the first month of storage, a phenomenon that is due to both the humidity of the environment and the preparation conditions. This modification can be minimized by preparing and storing tablets in low humidity conditions (lower that $10 \%$ ) or by preparation the formulations with a low effervescent mixture ratio (less than $25 \%$ ).

Keywords: foaming tablets, vaginal tablets, clotrimazole, experimental design, Box-Bhenken, stability studies

\section{INTRODUCTION}

Immediate release foaming vaginal tablets are used for local effect and appear to be useful dosage forms as they are easy to use and preparation. They are dosage forms that have been developed in order to obtain the widest possible spread of the drug substance on the mucosal surface and in its microgrids $[1,2]$. Foaming vaginal tablets are preferred because 
they avoid excessive lubrication and leakage from the vaginal cavity, while allowing a uniform dose spread over the entire mucosal surface, ensuring rapid disintegration over a large are $[1,3,4]$. Some authors state that if a preparation containing effervescent mixture is applied to a mucosa, it may even cause an increase in the absorption of the drug substance, mainly by reducing the thickness and viscosity of the mucous layer; alteration of fine junctions between cells, induction of changes in the structure of cell membranes and increase of the hydrophobic environment in the cell membrane $[5,6,7]$.

Foaming vaginal tablets are obtained by incorporating into the formulation an effervescent mixture and a surfactant foaming agent. Their disadvantage is their low stability at humidity, requiring special conditions of preparation and storage $[8,9,10]$. Their control includes special determinations, such as: humidity, carbon dioxide released by effervescence, the volume of foam generated in a minimum volume of simulated vaginal fluid $[11,12]$.

In a previous study an optimal formulation of foaming vaginal tablets was developed using a Box-Bhenken experimental design. The optimal formulation contains: $0.5 \%$ sodium laurylsulphate, $44 \%$ total amount of effervescent mixture and $24 \%$ excess of citric acid in the effervescent mixture [13].

Continuing this study, the aim of the present work was to evaluate the stability over time after of the foaming vaginal tablets stored under normal environmental thermo-hygrometric conditions. All the formulations prepared according with the Box-Bhenken experimental design were packaged in tightly sealed bottles with anhydrous sodium sulphate as desiccant and storage in normal thermo-hygrometric conditions (temperature of $25^{\circ} \mathrm{C}$, relative humidity $40-75 \%$ ).

TABLE 1. Formulation factors that influence the characteristics of foaming vaginal tablets (independent variables)

\begin{tabular}{|l|c|c|c|c|}
\hline \multirow{2}{*}{ Formulation variable } & \multirow{2}{*}{ Symbol } & \multicolumn{3}{|c|}{ Levels } \\
\cline { 3 - 5 } & & -1 & 0 & +1 \\
\hline $\begin{array}{l}\text { Sodium laurylsulphate } \\
\text { ratio (\%) }\end{array}$ & $\mathrm{X} 1$ & 0.5 & 1 & 1.5 \\
\hline $\begin{array}{l}\text { Effervescent mixture } \\
\text { ratio (\%) }\end{array}$ & $\mathrm{X} 2$ & 25 & 45 & 65 \\
\hline $\begin{array}{l}\text { Citric acid excess in the } \\
\text { effervescent mixture } \\
\text { (\%) }\end{array}$ & $\mathrm{X} 3$ & 5 & 15 & 25 \\
\hline
\end{tabular}

Immediate after preparation, after 1 and 3 months the tablets pharmaceutical characteristics were analysed and modification over time evaluated. In the same time the optimal formulation was stored in low hygrometric conditions (relative humidity below 10\%) and the results were compared with those obtained in normal thermo-hygrometric conditions.

\section{MATERIALS AND METHODS}

\section{Materials}

Clotrimazole (Beijing Double Crane Pharmaceutical Co. Ltd-China) as dug substance; sodium hydrogen carbonate, anhydrous sodium carbonate and citric acid form Chimopar (Romania) as effervescent mixture; sodium laurylsulphate from Loba Feinchemie (Austria) as foaming agent; Ludipress from BASF (Germany) as direct compression filler; low viscosity Methocel E15-LV-EP, from Colorcon LTD (U.K) as direct compression binder; fumed silica form Evonik (Germany) and magnesium stearate from Union Derivan (Spain) as flowing agents.

\section{Apparatus}

Erweka RM powder mixer with infinite movement (Germany); Erweka SVM powder density tester (Germany); Erweka GTD powder flowing tester (Germany); Korsch EK-0 exocentric tablet press (Germany); Monsanto tablets hardness tester (Italy); Erweka TA tablets friability tester; special device to study the volume and the resistance of the foam; Ohaus MB45 humidity balance (SUA); Mettler-Toledo Quatro MP 225 pH-meter (Switzerland); Elma 700 ultrasonics bath (Germany); VEB MLW sieves set for particle size analyser (Germany)l; Agilent 1100 HPLC system with UV detector (SUA); HPLC column Zorbax -SB-C8 (SUA); Binder climatic chamber (Germany)

\section{Experimental design and software}

A Box-Bhenken fractionated experimental design with three levels and three factors and was used to perform the study. Experimental design building, statistical parameters and coefficients calculation in order to evaluate the experimental data were performed using Modde 12 software (Sartorius Stedim Data Analytics AB, Sweden). The formulation factors (independent variables) including the levels of variation are presented in table 1.

The matrix of the experimental design is presented in Table 2. 
TABLE 2. The experimental design matrix

\begin{tabular}{|c|c|c|c|c|}
\hline Exp.Name & Run Order & X1 & X2 & X3 \\
\hline N1 & 7 & 0.5 & 25 & 15 \\
\hline N2 & 1 & 1.5 & 25 & 15 \\
\hline N3 & 10 & 0.5 & 65 & 15 \\
\hline N4 & 13 & 1.5 & 65 & 15 \\
\hline N5 & 11 & 0.5 & 45 & 5 \\
\hline N6 & 12 & 1.5 & 45 & 5 \\
\hline N7 & 3 & 0.5 & 45 & 25 \\
\hline N8 & 8 & 1.5 & 45 & 25 \\
\hline N9 & 5 & 1 & 25 & 5 \\
\hline N10 & 2 & 1 & 65 & 5 \\
\hline N11 & 4 & 1 & 25 & 25 \\
\hline N12 & 6 & 1 & 65 & 25 \\
\hline N13 & 15 & 1 & 45 & 15 \\
\hline N14 & 14 & 1 & 45 & 15 \\
\hline N15 & 9 & 1 & 45 & 15 \\
\hline
\end{tabular}

X1 - sodium laurylsulphate ratio, X2 effervescent mixture ratio, X3 Citric acid excess in the effervescent mixture

\section{METHODS}

The composition and the preparation of the foaming vaginal tablets

The composition of the foaming vaginal tablets: 100 $\mathrm{mg}$ clotrimazole as active pharmaceutical ingredient (10\% in a $1 \mathrm{~g}$ tablet weight); $15-65 \%$ (according with experimental design matrix) the effervescent mixture with alkaline component consist in sodium hydrogen carbonate and anhydrous sodium carbonate ( $10 \%$ from alkaline amount) and acid component consist in citric acid in an excess between 5 and 15\% (according with experimental design matrix) to obtain an acidic $\mathrm{pH}$ after foaming; 0.5-1.5\% (according with experimental design matrix) sodium laurylsulphate as foaming agent; 2\% Methocel E15 as binder, 1\% magnesium stearate as lubricant, $1 \%$ fumed silica as flowing agent and foam resistance enhancer, and the difference to the tablets weight Ludipress as filler agent.

The foaming vaginal tablets were obtained by direct compression normal in environmental thermohygrometrical conditions (temperature $20-25^{\circ} \mathrm{C}$ and $40-75 \%$ relative humidity), using a Korsch EK 0 eccentric tablet press, equipped with biconvex round shaped set punch and die with $12 \mathrm{~mm}$ diameter. Before tableting, the powder blend was dried until a $0.5 \%$ humidity in an oven at $40^{\circ} \mathrm{C}$. The tablet press has been set to obtain tablets that meet the pharmacopeial requirements regarding the weight $(1,000 \mathrm{mg} \pm 5)$ and content uniformity.

\section{Determination of the tablets' characteristics,} (dependent variables or responses of the experimental design)

In order to obtain the optimal formula, a number of 29 responses, for evaluation the most important characteristics of the powder blend for tableting and the characteristics foaming vaginal tablets were studied. There were determined using European Pharmacopeia procedure [14]: flowability characteristics of powders mixture (flowing time, Carr index and Hausner ratio); tablets' hardness and friability using apparatus presented above.

The volume of the foam and resistance of the foam resulted after tablets disintegration were determined follow an adapted method and device described in the literature [3]. A calibrated glass test tube suspended from a ring stand in a constant temperature bath at $37 \mathrm{oC}$. A $1 \mathrm{~g}$ rubber cylinder suspended by a thread, that could be gently lowered onto the surface of the foam, when the foam attained the maximal possible volume, and can determine the time until the foam will be collapsed by the $1 \mathrm{~g}$ weight. $5 \mathrm{ml}$ simulated vaginal fluid (SVF) at $370 \mathrm{C}$ were pipetted into the tube. The tablet was dropped into the tube and the maximum expand volume of the foam was recorded. After reaching the maximum expanded volume the rubber cylinder weighting $1 \mathrm{~g}$ was placed on the surface of the foam and the time until the foam no longer supports the weight and settled to the bottom of the tube where recorded as resistance of the foam.

The mass of carbon dioxide released during of 20 minutes foaming in $30 \mathrm{ml}$ simulated vaginal fluid (SVF) at $370 \mathrm{C}$ was determined using a gravimetric method described by the literature $[15,16]$.

The $\mathrm{pH}$ generated in the following mediums $(30 \mathrm{ml}$ at $37 \mathrm{oC}$ ): distilled water, simulated vaginal fluid (SVF) $\mathrm{pH}$

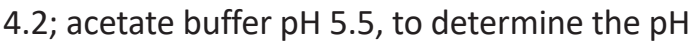
generated by the tablet itself, but also to observe if the foaming vaginal tablet formulations have a capacity to change an eventually local pH buffer effect. 
The humidity of the powder mixture for tableting and of the tablets was determined, according with European Pharmacopeia procedure using a humidity balance Ohaus MB 45 (USA).

The determinations on powder blend for tableting were performed with several minutes before tableting and on tablets immediate after tableting. Those results were subject of the work already published [13]. The determinations on tablets were repeated after 1 and 3 months on the tablets packaged in tightly sealed bottles with anhydrous sodium sulphate as desiccant and stored under normal environmental thermo-hygrometric conditions (temperature $20-25^{\circ} \mathrm{C}$ and $40-75 \%$ relative humidity), in order to conclude the influence of the environment conditions on the formulation stability and are the subject of present work.

The described responses and the symbols used for interpretation of the data in the present study are represented in table 3.

The preparation and stability studies in normal thermo-hygrometrical conditions can assure us that the optimal formulation obtained will show maximal resistance to the environmental conditions during production and preservation.

\section{RESULTS AND DISCUSSIONS}

Tablets stability over time after storage under normal environmental thermo-hygrometric conditions

The results regarding the properties of powder blend for tableting and foaming tablets right after compression were already published [13]. The results obtained after 1 and 3 months storage of the vaginal foaming tablets (in normal thermo-hygrometrical conditions) are presented tables 4 and 5. The experimental data showed that the tablets suffered important changes in their characteristics during storage. These changes are in the direction of lowering the quality of the tablets, so in the case of this pharmaceutical dosage form, the lack of stability in time can be considered as a real danger. The differences between the responses are greater between the preparation time and the first month than between 1 month and 3 months, so the foaming vaginal tablets suffered a fast modification of their characteristics during the first month, and a slower changing of the characteristics in the following months.
TABLE 3. Dependent variables (responses) determined on tablets after 1and 3 month storage in normal environmental thermo-hygrometric conditions

\begin{tabular}{|c|c|c|}
\hline Number & Responses & Symbols \\
\hline 1 & Tablets hardness - after 1 month (kg) & Y13 \\
\hline 2 & Foaming time - after 1 month (min) & Y14 \\
\hline 3 & $\begin{array}{c}\text { Maximum volume of the foam - after } 1 \\
\text { month (ml) }\end{array}$ & Y15 \\
\hline 4 & $\begin{array}{l}\text { Resistance of the foam - after } 1 \text { month } \\
\text { (min) }\end{array}$ & Y16 \\
\hline 5 & $\begin{array}{l}\text { Mass of carbon dioxide released by } \\
\text { foaming - after } 1 \text { month }(\mathrm{g})\end{array}$ & Y17 \\
\hline 6 & $\mathrm{pH}$ generated in water - after 1 month & Y18 \\
\hline 7 & $\mathrm{pH}$ generated in SVF - after 1 month & Y19 \\
\hline 8 & Tablets hardness - after 3 months (kg) & Y20 \\
\hline 9 & Foaming time - after 3 months (min) & Y21 \\
\hline 10 & $\begin{array}{l}\text { Maximum volume of the foam - after } 3 \\
\text { months }(\mathrm{ml})\end{array}$ & Y22 \\
\hline 11 & $\begin{array}{l}\text { Resistance of the foam - after } 3 \text { months } \\
\text { (min) }\end{array}$ & Y23 \\
\hline 12 & $\begin{array}{l}\text { Mass of carbon dioxide released by } \\
\text { foaming - after } 3 \text { months (g) }\end{array}$ & Y24 \\
\hline 13 & $\mathrm{pH}$ generated in water - after 3 months & Y25 \\
\hline 14 & $\begin{array}{l}\text { Humidity pf the powders mixture right } \\
\text { before compression }\end{array}$ & Y26 \\
\hline 15 & $\begin{array}{l}\text { Humidity of the foaming tablets right } \\
\text { after compression }\end{array}$ & Y27 \\
\hline 16 & $\begin{array}{l}\text { Difference of the tablets' humidity after } \\
\qquad 1 \text { month }\end{array}$ & Y28 \\
\hline 17 & $\begin{array}{l}\text { Difference of the tablets' humidity after } \\
\qquad 3 \text { months }\end{array}$ & Y29 \\
\hline
\end{tabular}

According with obtained results obtained on humidity of powders blend and tablets, there are little differences between the humidity of powder mixture before compression and the humidity of the resulted tablets. Considering the initial humidity of the powders mixture was in all cases was below $0.5 \%$ after drying, it can be concluded that during the compression process a humidity absorption phenomenon takes place and the amount of humidity absorbed is independent on the formulation and 
TABLE 4. Matrix of the responses obtained on tablets after 1 and 3 months storage in normal environmental thermo-hygrometric conditions

\begin{tabular}{|c|c|c|c|c|c|c|c|c|c|c|c|c|c|c|}
\hline Exp Name & Y13 & Y14 & Y15 & Y16 & Y17 & Y18 & Y19 & Y20 & Y21 & Y22 & Y23 & Y24 & Y25 & Y20 \\
\hline N1 & 13 & 7 & 8 & 0.016 & 0.21 & 5.54 & 5.2 & 13 & 8 & 8 & 0.016 & 0.2 & 5.31 & 13 \\
\hline N2 & 11.5 & 26 & 4 & 0.016 & 0.191 & 6.03 & 5.07 & 11.5 & 46 & 3 & 0.016 & 0.181 & 6.22 & 11.5 \\
\hline N3 & 15.5 & 9 & 13 & 16 & 0.297 & 5.1 & 4.5 & 16 & 12.5 & 8 & 18 & 0.257 & 5.21 & 16 \\
\hline N4 & 14.5 & 17 & 10 & 21.5 & 0.26 & 4.93 & 4.42 & 15.5 & 30 & 8 & 23 & 0.214 & 4.84 & 15.5 \\
\hline N5 & 9.5 & 4 & 11 & 12.5 & 0.2 & 5.66 & 5.16 & 10 & 5.6 & 14 & 14 & 0.18 & 5.4 & 10 \\
\hline N6 & 10 & 9.5 & 9 & 33.5 & 0.197 & 6.1 & 5.15 & 11 & 12.5 & 9 & 30 & 0.177 & 6.1 & 11 \\
\hline N7 & 13.5 & 6 & 6 & 12.5 & 0.23 & 4.61 & 4.6 & 13.5 & 7 & 5 & 15 & 0.207 & 4.41 & 13.5 \\
\hline N8 & 12.5 & 9.5 & 11.5 & 30 & 0.205 & 4.56 & 4.6 & 12.5 & 11 & 11 & 28 & 0.18 & 4.27 & 12.5 \\
\hline N9 & 12 & 12 & 8 & 0.016 & 0.19 & 6.39 & 5.22 & 11 & 32 & 8 & 0.016 & 0.187 & 6.33 & 11 \\
\hline $\mathrm{N} 10$ & 14.5 & 11 & 10.5 & 17.5 & 0.245 & 5.8 & 4.86 & 15 & 18 & 10 & 16 & 0.209 & 5.9 & 15 \\
\hline N11 & 10 & 27 & 5 & 0.016 & 0.206 & 5.28 & 4.71 & 10 & 47 & 3 & 0.016 & 0.195 & 5.22 & 10 \\
\hline $\mathrm{N} 12$ & 12.5 & 16 & 9 & 19 & 0.275 & 4.07 & 4.41 & 14.5 & 32 & 7.5 & 20 & 0.225 & 4.1 & 14.5 \\
\hline N13 & 12.5 & 8.5 & 11 & 20.2 & 0.214 & 5.28 & 4.49 & 13.5 & 15.2 & 10.5 & 19.4 & 0.193 & 5.43 & 13.5 \\
\hline N14 & 13 & 9.2 & 12.5 & 21.5 & 0.207 & 5.41 & 4.62 & 13 & 16.5 & 11.5 & 21.8 & 0.187 & 5.29 & 13 \\
\hline N15 & 13.5 & 7.4 & 11.5 & 23 & 0.212 & 5.32 & 4.55 & 14 & 13.3 & 11 & 23.5 & 0.191 & 5.51 & 14 \\
\hline
\end{tabular}

Y13 - tablets hardness after 1 month, Y14 - foaming time after 1 month, Y15 - maximum volume of the foam after 1 month, Y16 - resistance of the foam after 1 month, Y17 - mass of carbon dioxide released by foaming after 1 month, $\mathrm{Y} 18-\mathrm{pH}$ generated in water after $1 \mathrm{month}, \mathrm{Y} 19-\mathrm{pH}$ generated in SVF after 1 month; Y 20 - tablets hardness after 3 month, Y 21 - foaming time after 3 month, Y 22 - maximum volume of the foam after 3 month, Y 23 - resistance of the foam after 3 month, Y 24 - mass of carbon dioxide released by foaming after 3 month, Y 25 - pH generated in water after 3 month

probably depends on the environmental termohygrometrical conditions [17]. Similar differences are also between the humidity after compression and the humidity after 1 and 3 months respectively. In most of the cases the humidity became higher during the storage, but there are some formulations for which after 1 and 3 month the humidity became lower. The final humidity of the vaginal foaming tablets is between 0.61 and $2.59 \%$.

\section{Fitting of the experimental design data}

Fitting of experimental data was performed with the Modde software, using the Partial Least Squares (PLS) regression method. The obtained results are show as histograms in figures 1, 2, 3. 
TABLE 5. Matrix of the responses obtained for the study of the humidity

\begin{tabular}{|c|c|c|c|c|c|c|}
\hline $\begin{array}{l}\text { Exp } \\
\text { Name }\end{array}$ & Y26 & Y27 & Humidity after & Y16 & Y17 & Y18 \\
\hline 1 month & $\begin{array}{l}\text { Humidity } \\
\text { after }\end{array}$ & 7 & 8 & 0.016 & 0.21 & 5.54 \\
\hline $\begin{array}{c}3 \\
\text { months }\end{array}$ & Y28 & Y29 & 4 & 0.016 & 0.191 & 6.03 \\
\hline N1 & 0.83 & 1.18 & 1.01 & 0.61 & 0.14 & 0.03 \\
\hline N2 & 1.01 & 2.17 & 2.10 & 1.69 & 0.24 & 0.12 \\
\hline N3 & 1.12 & 1.57 & 2.17 & 2.42 & 0.91 & 1.45 \\
\hline N4 & 1.5 & 1.67 & 2.27 & 2.59 & 0.91 & 1.52 \\
\hline N5 & 1.28 & 1.43 & 1.62 & 1.83 & 0.50 & 1.00 \\
\hline N6 & 2.07 & 2.25 & 2.34 & 2.44 & 0.40 & 0.79 \\
\hline N7 & 0.75 & 0.82 & 1.32 & 1.42 & 0.81 & 1.20 \\
\hline N8 & 1.18 & 1.15 & 1.45 & 1.65 & 0.61 & 1.10 \\
\hline N9 & 1.06 & 1.20 & 0.90 & 0.82 & 0.01 & 0.22 \\
\hline N10 & 0.87 & 0.80 & 1.40 & 1.60 & 0.91 & 1.40 \\
\hline N11 & 1.00 & 0.91 & 0.88 & 0.96 & 0.28 & 0.65 \\
\hline N12 & 0.77 & 0.94 & 1.56 & 1.05 & 0.93 & 0.71 \\
\hline N13 & 1.33 & 1.27 & 1.67 & 1.77 & 0.61 & 1.00 \\
\hline N14 & 1.41 & 1.40 & 1.72 & 1.82 & 0.53 & 1.09 \\
\hline N15 & 1.37 & 1.34 & 1.65 & 1.73 & 0.58 & 0.89 \\
\hline
\end{tabular}

Y26 - humidity of the powders mixture right before compression (\%); Y27 - humidity of the tablets right after compression (\%), Y28 - difference of the tablets' humidity after 1 month, Y29 - difference of the tablets' humidity after 3 months

According with histogram fitting data and ANOVA analysis (data not shown) the results are good for most of the responses $(\mathrm{p}<0.05$ for the model and $p>0.05$ for the error). Poorly fitting was found for the following responses: $Y 13$ (tablets hardness after 1

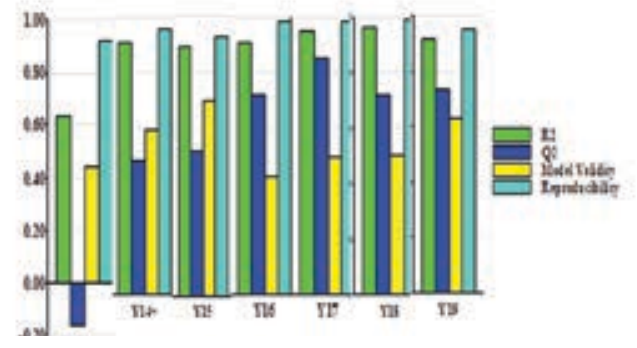

FIGURE 1. Histogram representing the fitting of the data after one month storage in normal environmental thermo-hygrometric conditions

Y13 - tablets hardness after 1 month, Y14 - foaming time after 1 month, Y15 - maximum volume of the foam after 1 month, Y16 - resistance of the foam after 1 month, Y17 - mass of carbon dioxide released by foaming after 1 month, $Y 18-p H$ generated in water after 1 month, Y19-pH generated in SVF after 1 month

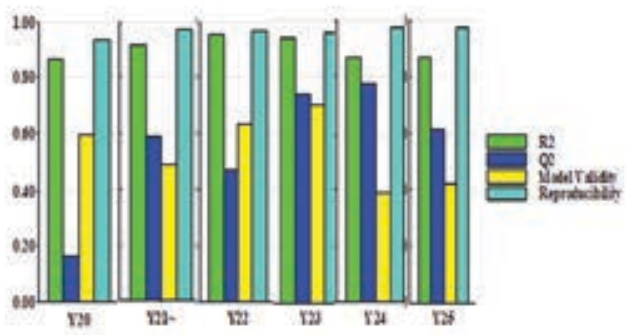

FIGURE 2. Histogram representing the fitting of the data after 3 months storage in normal environmental thermo-hygrometric conditions

Y20 - tablets hardness after 3 month, Y21-foaming time after 3 month, Y22 - maximum volume of the foam after 3 month, Y23-resistance of the foam after 3 month, Y24 - mass of carbon dioxide released by foaming after 3 month, Y25 - pH generated in water after 3 month

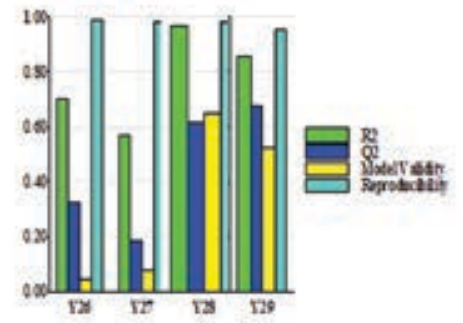

FIGURE 3. Histogram representing the fitting of the data concerning humidity studies

Y26 - humidity of the powders mixture right before compression (\%); Y27 - humidity of the tablets right after compression (\%), Y28 - difference of the tablets' humidity after 1 month, Y29-difference of the tablets' humidity after 3 months 

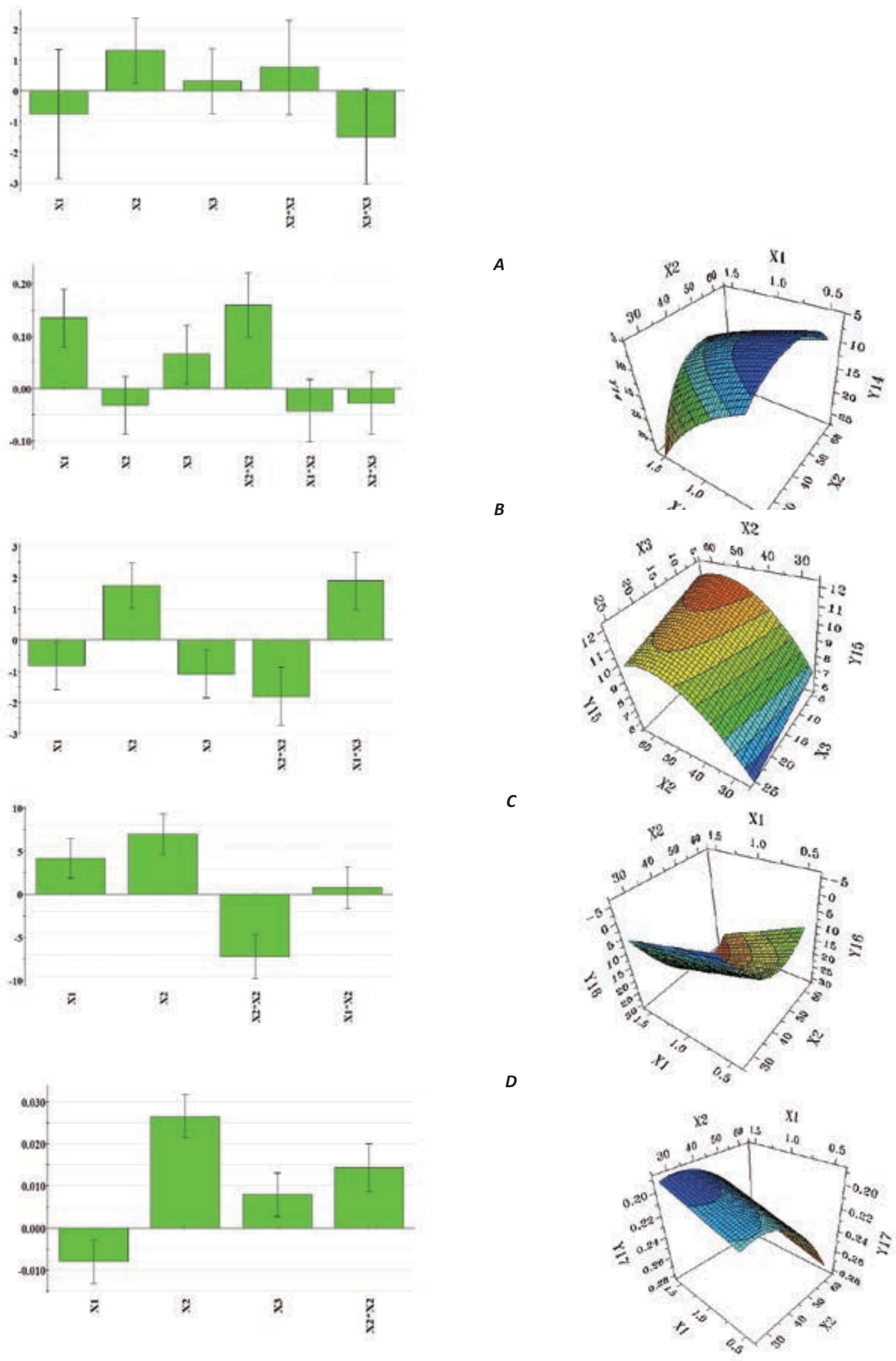

$E$ 

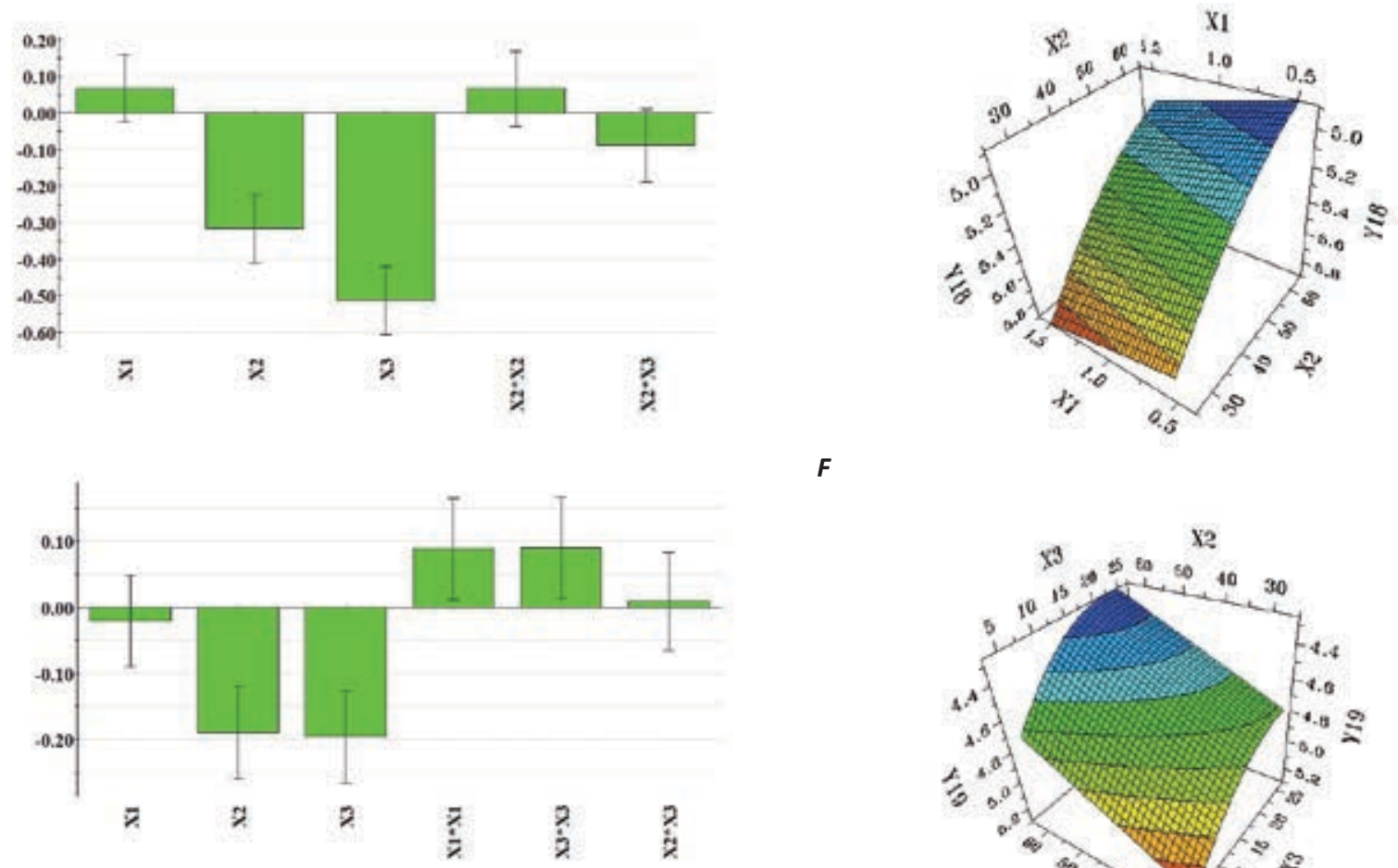

$\boldsymbol{F}$

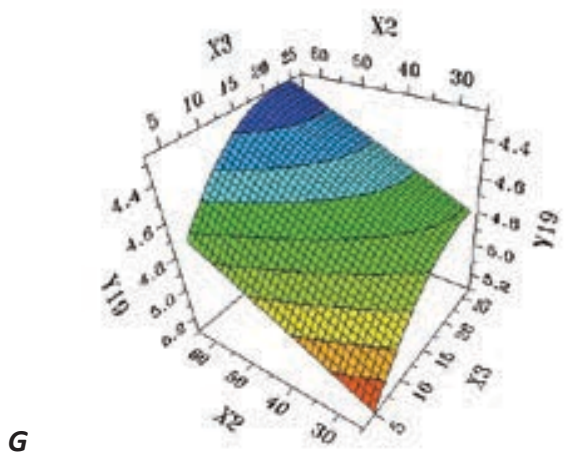

FIGURE 4. The influence of formulation factors on tablets properties after 1 month storage on under normal environmental thermo-hygrometric conditions

$a$-tablets hardness after 1 month, $b$-foaming time after 1 month, $c$-maximum volume of the foam after 1 month, $d$-resistance of the foam after 1 month, $e-$ mass of carbon dioxide released by foaming after 1 month, $f-p H$ generated in water after 1 month, $g-p H$ generated in SVF after 1 month

month) with values of $p$ being 0.067 for the model and 0.108 for the error; Y26 (humidity of the powders mixture right before compression) with values of $p$ being 0.03 for the model and 0.022 for error; Y27 (humidity of the tablets right after compression) with values of $p$ being 0.124 for the model and 0.025 for error. Another method for the evaluation of the fitting is by drawing the dependence curves between the obtained values and the values predicted by the model [18-20]. Using this method, the best fitting obtained for the following responses Y14, Y16, Y17, Y18, Y20, Y21, Y23, Y24, Y28, and Y29 (data not shown).

The influence of formulation factors on tablets after one month storage under normal environmental thermo-hygrometric conditions

Considering the fitting results for tablets hardness after 1 month (Y13), value of $p$ - for model $=0.067>$ 0.05 , the data obtained are not very relevant.
However, it was observed the tablets hardness increases with increasing the ratio of effervescent mixture (Fig. 4a). By comparing the results obtained immediately after compression with those obtained after one month of storage, it is also observed that the tablets hardness shows an increasing tendency over time, and this increase is all the more pronounced as the ratio of effervescent mixture in the formulation is higher. Thus, for $25 \%$ effervescent mixture, a tendency to decrease the tablets hardness is obtained with differences of the order of $-0.5 ;-2 \mathrm{~kg}$, while for higher percentages of effervescent mixture an increase of the mech tablets hardness is obtained, the differences being of the order $+2,+5.5 \mathrm{~kg}$ for concentrations of $45 \%$ effervescent mixture and $+5.5-+7 \mathrm{~kg}$ for concentrations of $65 \%$ effervescent in mixture.

These changes suggest that during storage there are interactions between the components of the effervescent blend, which are greater the closer the contact between the two components of the mixture, 
so the higher the ratio of the effervescent mixture it is. In the case of the ratio of $25 \%$ effervescent mixture, the ratio being small, the interactions between the components become less possible and thus the tablets hardness does not increase in time. It is also observed that this increase in tablets hardness over time is accentuated by the increase in the ratio of excess citric acid in the formulation, which is explainable because citric acid is a hygroscopic substance, attracts more water by storage, and water is the substrate of interactions between components of the effervescent mixture. We also mention that this increase in tablets hardness over time has a negative effect on disaggregation and foaming, so it is an undesirable effect.

The foaming time shows (Y14) the same trends of variation after one month of storage (Fig 4.b), as immediate after preparation, but the values obtained are higher after one month storage, observing an increase between 1.5-13 minutes, depending on the formulation. This increasing can also be explained by the increase of the tablet's hardness in time, this leading to a slower disintegration. There is a trend of nonlinear variation for factor $\mathrm{X} 2$ (effervescent mixture ratio), a trend observed in the analysis after preparation, the graph showing in both cases a minimum of $45 \%$ effervescent mixture.

Regarding the maximum volume of the foam the results show at one month - Y15 (Fig 4.C) the same tendencies of influence of the formulation factors as immediate after preparation, but the influence of the effervescent mixture ratio is lower, and a nonlinear dependence it is observed. However, the main effect remains the effervescent mixture ratio, and according with 3D graph (Fig 4.c) a maximum effect at $45 \%$ effervescent mixture is observed, over that the foam volume probably decreases by decreasing the foaming capacity of the tablets, due to interactions between effervescent components.

Fig 4.d shows the influence of the formulation factors on the resistance of the foam generated by the tablets after one month of storage (Y16). It can be observed that after one month of storage, the influence of the sodium laurylsulphate ratio and the influence of the effervescent mixture ratio on the foam resistance increase, maintaining the nonlinear dependence in the case of effervescent mixture. An interesting phenomenon is the increase in the resistance of the foam generated by the tablets stored one month, compared to the resistance of the foam generated by the tablets immediate after preparation is dependent on the effervescent mixture ratio. This increase is more pronounced at higher concentrations of effervescent mixture, with 5-10minute increase for $45 \%$ effervescent mixture, $11-15$ minute increase for $65 \%$ effervescent mixture and a decrease of -3-1.5 minutes for tablets with $25 \%$ effervescent mixture. The fact that the influence of the sodium laurylsulphate ratio is lower and effervescent mixture is higher, shows that in maintaining stability over time, the decisive factor is the effervescent mixture ratio.

Fig 4.e shows the influence of the formulation factors on the mass of carbon dioxide released after foaming by the tablets, after one month storage (Y17). The results show that after one month storage, the formulation factors exert the same tendency to influence this response, but over time, the influence of the effervescent mixture ratio decreases and the three-dimensional graph has the same appearance as the results obtained immediate after preparation. Regarding the differences obtained from the determinations after 1 month storage, there is a decrease of the mass of carbon dioxide released after foaming, which is explained by the phenomenon of slow in situ interaction between the components of the effervescent mixture during storage that leads to the release of some of the carbon dioxide during storage. The decrease in the mass of carbon dioxide after storage increases with the increase of the effervescent mixture ratio in the formulation, obtaining differences of 0.01-0.035 grams for $25 \%$ effervescent mixture; 0.06-0.075 grams for $45 \%$ effervescent mixture and $0.11-0.15$ grams for $65 \%$ effervescent mixture. It can conclude that the stability over time of the tablets decreases with increasing the effervescent mixture ratio, given that the mass of the carbon released after foaming is the main measure of stability over time for foaming tablets.

Fig 4.f. shows the influence of the formulation factors on the $\mathrm{pH}$ generated in water by vaginal tablets after one month of storage (Y18). The results show that after one month of storage no significant changes in the dependence of this variable on the formulation factors was observed, the $\mathrm{pH}$ decreasing in this case as the excess of citric acid and the effervescent mixture ratio increase, to the same extent as immediate after preparation. The sodium laurylsulphate ratio has no influence on $\mathrm{pH}$ generated. The three-dimensional graph has a shape like that obtained from the analysis 
of tablets immediately after preparation. Analysing the evolution over time of this factor, it cannot be said that there is a general trend of increase or decrease over time, obtaining both decreases and increases for certain formulations, but the variations are relatively small (-0.29 - +0.18 pH units).

Fig 4.g shows the influence of the formulation factors on the $\mathrm{pH}$ generated in SVF (Y19), after one month of storage. After analysing the results and comparing with those obtained immediate after preparation, it can be said that after one month of storage it is a decrease in the influence of the excess citric acid and a trend towards a nonlinear dependence, but the trends of initial influence are maintained, the $\mathrm{pH}$ generated in SVF decreasing after one month storage with increasing the excess of citric acid and the effervescent mixture ratio. Not influence of the sodium laurylsulphate ratio was observed. Analysing the evolution over time of this response, even in this case there is no general tendency of decrease or increase of values over time, obtaining both increases and decreases, the variations being relatively small $(-0.13-+0.19 \mathrm{pH}$ units). This behaviour is similar to that obtained for $\mathrm{pH}$ in water.

The influence of formulation factors on tablets after 3 months storage under normal environmental thermo-hygrometric conditions

The influence of the formulation factors on the tablets hardness after three months storage (Y20), are presented in Fig 5.a. The results show that the tablets hardness, are influence by the same formulation factors as that after one month storage, the hardness increase with
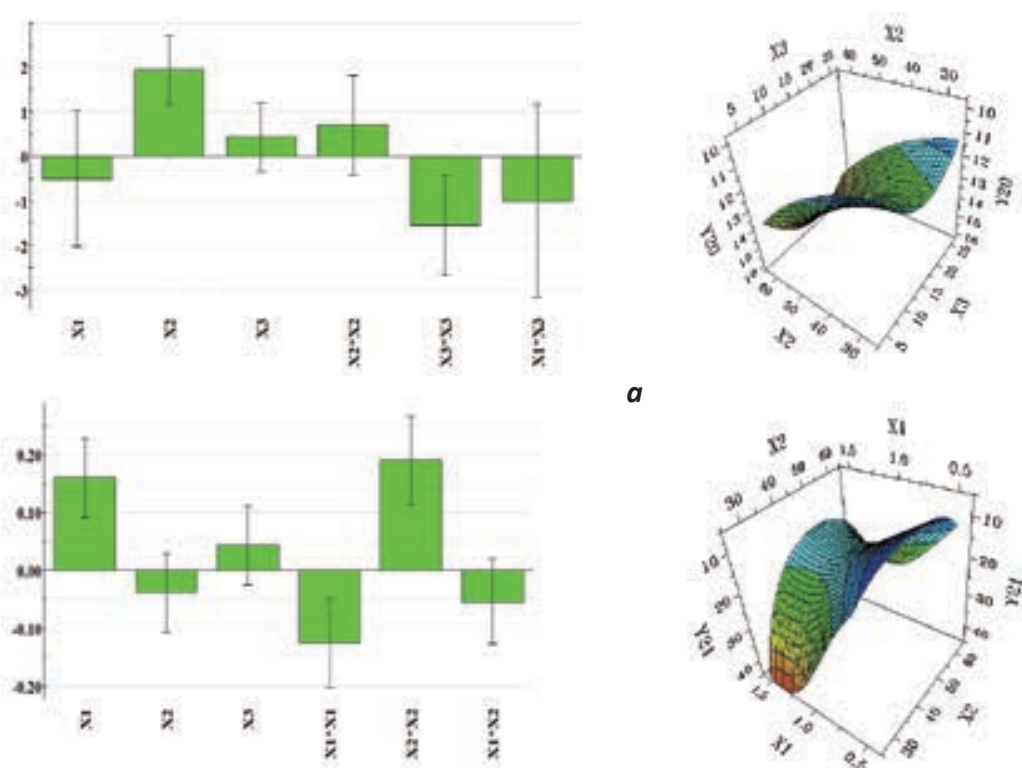

$a$

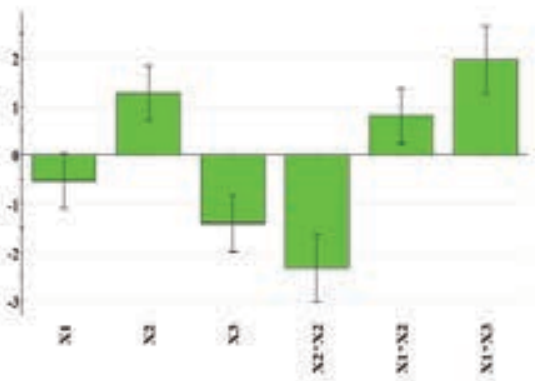

$\boldsymbol{b}$
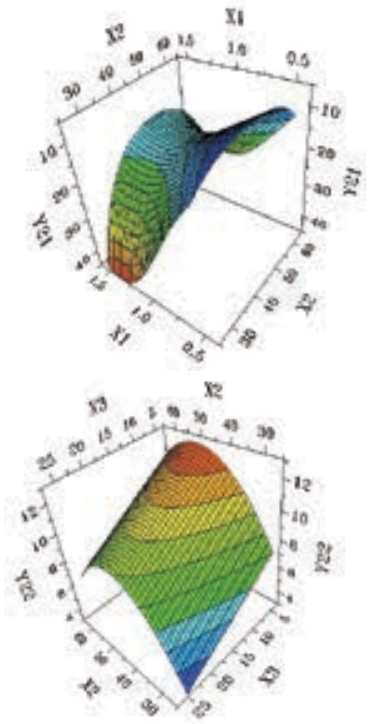

c

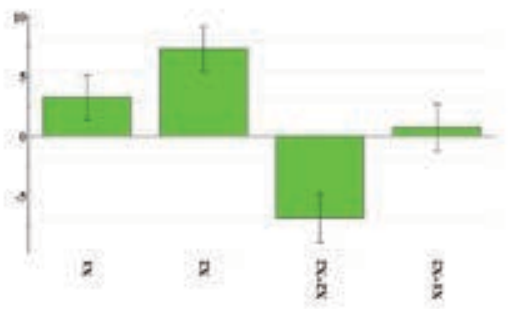

x?

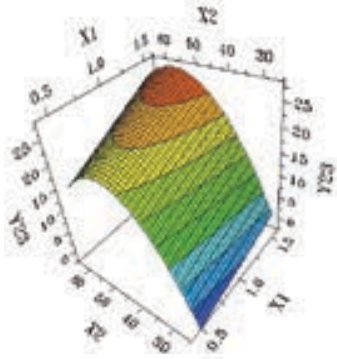

d
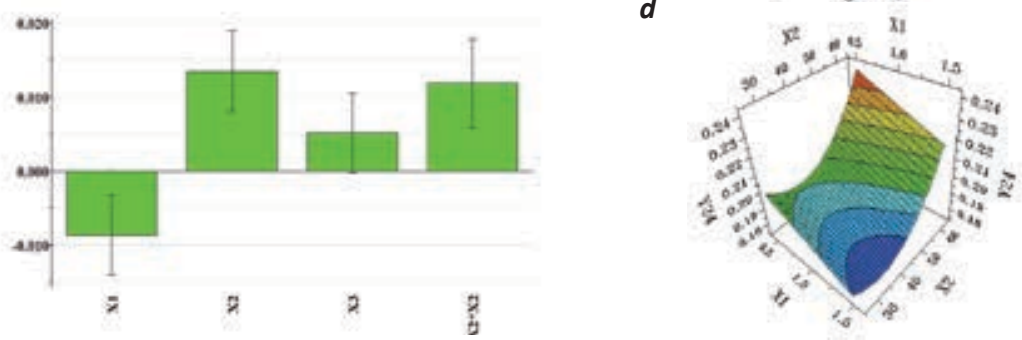

e
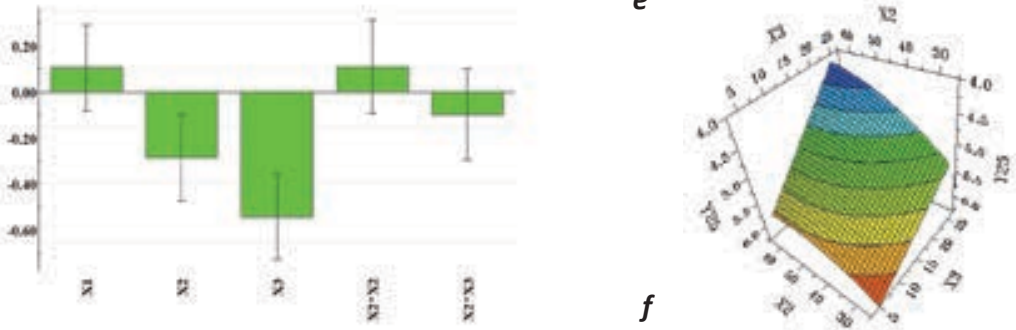

FIGURE 5. The influence of formulation factors on tablets properties after 3 months storage on under normal environmental thermo-hygrometric conditions

$a$-tablets hardness after 3 months, $b$-foaming time after 3 months, $c$-maximum volume of the foam after 3 months, $d$-resistance of the foam after 3 months, $e-$ mass of carbon dioxide released by foaming after 3 months, $f-p H$ generated in water after 3 months 
increasing the effervescent mixture ratio, but in this case the model fitting is match better. Regarding the changes over time of this parameter, it cannot be seen high differences between the results obtained after one month and those obtained after three months, so after the first month storage the tablets hardness increase sharply, reaching fairly high values, which in the following months remain unchanged.

Fig 5.b. shows the influence of the formulation factors on the foaming time after three months storage (Y21). The results show that even after three months the foaming time increases with increasing sodium lauryl sulfate ratio and decreases with increasing effervescent mixture ratio in the formulation, the influence being nonlinear. The valuesobtained after three months storage are higher than those obtained after one month storage, and the differences between 1 and 3 months are higher than those obtained between 0 and one month. The highest stability over time in terms of foaming time was obtained for N1 formulation with $0.5 \%$ sodium lauryl sulfate, $25 \%$ effervescent mixture and $15 \%$ excess citric acid in in the formulation, for which increasing the foaming time was 3.5 minutes in 3 months.

The influence of the formulation factors on the maximum volume of foam after three months storage (Y22), are presented in Fig 5.c. The results show that the volume of foam is influenced in the same way after three months of storage as after one month of storage, it increases with increasing the effervescent mixture ratio and it decrease with increasing citric acid excess. The three-dimensional graph has a shape similar to that obtained on after one month storage. The values are slightly lower than those obtained after one month, and the changes between one month and three months are smaller than those in the first month, so after an abrupt initial change, the values remain almost unchanged over time. The highest stability over time in terms of the maximum volume of foam was obtained for the $\mathrm{N} 1$ formulation with $0.5 \%$ sodium lauryl sulfate; $25 \%$ effervescent mixture and $15 \%$ excess citric acid in the formulation, that remained constant during the 3 months of study.

Fig 5.d. shows the influence of the formulation factors on the resistance of the foam formed by the tablets after three months storage (Y23). The influence of the studied factors on the resistance of the foam after three months storage is similar as after one month storage, it increase with increasing the sodium laurylsulphate ratio and effervescent mixture ratio. The variations of this parameter after 3 months are much smaller than after first month, so in the case of this parameter the major changing take place in the first month storage. The highest stability over time in terms of the resistance of the generated foam was obtained for the $\mathrm{N} 6$ formulation with $1.5 \%$ sodium lauryl sulfate, $45 \%$ effervescent mixture and $5 \%$ excess citric acid in the in the formulation, for which it was 5 minutes increase after the three months of the study. The lowest stability over time was for the N4 formulation with $1.5 \%$ sodium lauryl sulphate; $65 \%$ effervescent mixture and $15 \%$ excess citric acid in the formulation, with.16.5 minutes increasing of the resistance of the foam formed by the tablets after three months storage.

The influence of the formulation factors on the mass of carbon dioxide released after foaming by the tablets after three months storage (Y24) is presented in Fig 5.e. The influence is the same as after one months storage, with the observation that the differences between zero and one month for the same formulation are greater than between 1 and 3 months. The highest stability over time in terms of the mass of carbon dioxide released was obtained for the $\mathrm{N} 9$ formulation with $1 \%$ sodium lauryl sulfate, $25 \%$ effervescent mixture and $5 \%$ excess citric acid in in the formulation, for which a decrease of $0.01 \mathrm{~g}$ in the mass of carbon dioxide released by foaming was observed after the three months storage.

Fig. 5.f. shows the influence of the formulation factors on the $\mathrm{pH}$ generated in the water by the tablets, after three months storage (Y25). According with the data the $\mathrm{pH}$ in water decrease as the excess of citric acid and the effervescent mixture ratio increase. Regarding the evolution over time of the $\mathrm{pH}$ in water of the foaming tablets, no significant changes are observed between 1 and 3 months, neither in terms of dependence on the formulation factors, nor in terms of the variation in values over time.

\section{The influence of formulation factors on the tablets humidity storage under normal environmental thermo-hygrometric conditions}

Because for the humidity of the powders mixture right before compression (Y26) and the humidity of the foaming tablets right after compression (Y27), no adequate fitting was obtained (Fig. 3), and the value of $p$ in the ANOVA test being 0.124 for the model and 0.025 for the error, means that these responses are 
influenced by other factors that those was studies in the experimental design, probably the environmental relative humidity and temperature. Further will be analysed the influence of the formulation factors only on the difference of the tablets' humidity after 1 month storage, respectively 3 months storage, for which adequate data fitting was obtained.

The influence of the formulation factors on the difference of the tablets' humidity after 1 month storage (Y28), is presented in Fig. 6.a. It is observed that the difference in humidity between 0 and one month mainly increases with increasing the effervescent
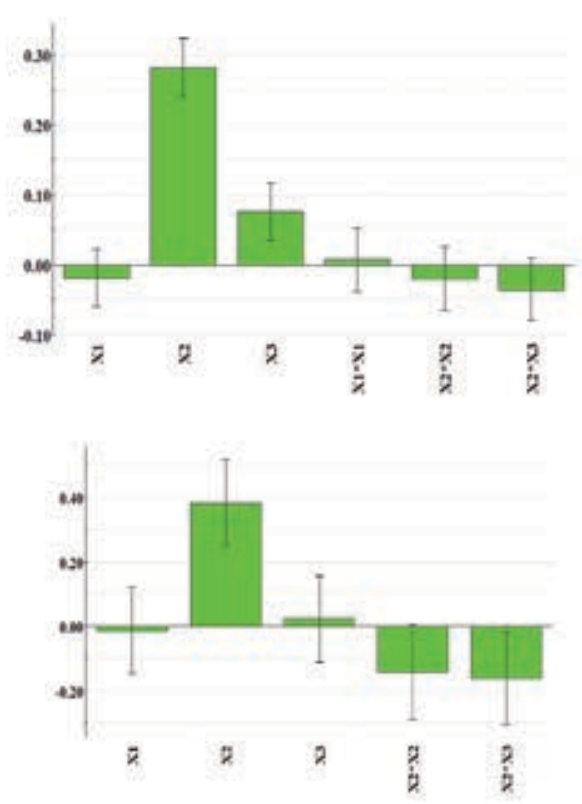

a
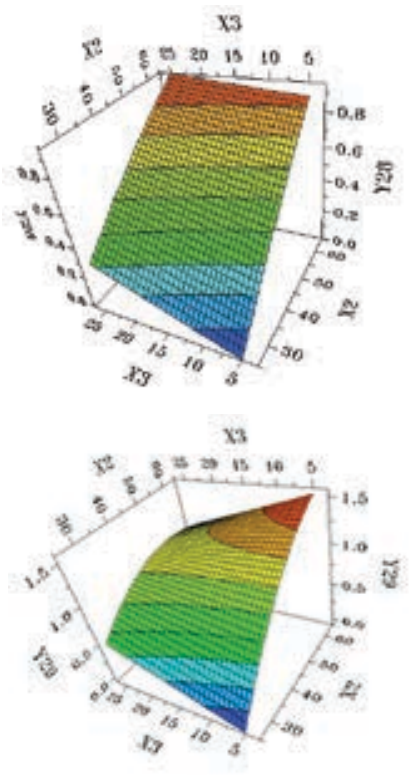

b

FIGURE 6. The influence of formulation factors on the difference of the tablets' humidity after 1 month storage (Y28 - a) and the difference of the tablets' humidity after 3 months storage (Y28 - b)

mixture ratio (X2) and to a lesser extent with increasing citric acid excess (X3). This influence is explained by the adsorption of water by effervescent mixture and citric acid during storage and by a process of slow effervescence with water formation, which takes place during storage. It should be noted that in the case of formulations with a $25 \%$ effervescent mixture, a decreasing in humidity were observed after one month storage, so in this case a faster process of water evaporation than its adsorption and in situ formation take place. From these data it can be concluded that tablets storage in the presence of anhydrous sodium sulphate has a beneficial influence, but good results are obtained only for formulations with a small effervescent mixture ratio in the formulation (25\%), for higher effervescent mixture ratio the effect of anhydrous sodium sulphate is not strong enough to counteract the water adsorption and its formation in situ.

Fig. 6.b. shows the influence of the formulation factors on the difference of the tablets' humidity after 3 months storage (Y29). After 3 months storage, the increase in the humidity has the same tendency as after one month, but it is influenced only by the effervescent mixture ratio (X2) in the formulation. Regarding the change in the humidity of foaming tablets, there is a theory that the process of the tablets' moisture increasing has two phases: a phase of adsorption of atmospheric moisture and a second phase of water formation by the process of slow effervescence in situ [17]. Based on this theory and on the results obtained, it can be explained the fact that in the initial storage phase (0-1 month) the influence of citric acid excess is higher, because the water hygroscopic substance, and in terms of global effect (0-3 months), the effervescent mixture ratio will have the decisive influence through the process of slow effervescence with water formation in situ, which takes place according to the theory, mainly in the second phase and it is a longer process than adsorption of atmospheric moisture. It is also observed that the change in humidity over time depends to a greater extent on the formulation factors than on the initial humidity of the tablets.

\section{Study of the influence of storage conditions on the stability over time of foaming vaginal tablets}

There are numerous studies published in the literature that indicate the maintenance of the stability over time of tablets in general, and of effervescent and foaming dosage forms in particular, it is influence by the preparation conditions, but also especially by the storage conditions (relative humidity and temperature) $[5,9,10,11,17,21,22]$.

In order to study this influence, the same formulation was kept for three months in two different conditions, namely: normal thermo-hygrometric conditions (temperature of $25^{\circ} \mathrm{C}$, relative humidity $40-75 \%$; in adsorption process takes place, citric acid being a 
tightly sealed bottles with anhydrous sodium sulphate as desiccant); and low hygrometric conditions (temperature of $25^{\circ} \mathrm{C}$, relative humidity below $10 \%$ provided anhydrous calcium chloride in a desiccator). For this study, a formulation with an intermediate behaviour in terms of stability over time was chosen namely the formulation N15 with $45 \%$ effervescent mixture, $15 \%$ citric acid excess $1 \%$ sodium laurylsulphate. The obtained results are presented in table 6.

The results obtained show that the stability of the tablets stored in lower humidity conditions is higher over time, their stability decreasing much more slowly even in the first month storage. An improvement in the stability of the foaming vaginal tablets can be obtained by storage them in environmental conditions with low relative humidity. This increase in stability translates into smaller differences obtained at one month and three months on tablets hardness, foaming time, maximum volume of the foam, resistance of the foam; the mass of $\mathrm{CO} 2$ released, the $\mathrm{pH}$ generated in the water, the $\mathrm{pH}$ generated in the SVF and difference in humidity, in comparison with the values obtained immediately after preparation. In conditions of low humidity, the absorption of moisture from the environment over time by the tablets is lower, this phenomenon is explained by the lack of water vapor in the storage medium, which are the substrate of the tablet degradation process by triggering in situ the effervescence process $[5,10,11,21,22,23]$.

\section{Improving the foaming effect}

Considering that sodium laurylsulfate has irritant effect at the concentration required to obtain a suitable foaming effect, it was tried to replace it with another foaming agent, namely Span60, a strong nonionic surfactant (sorbitan monostearate, with mass molecular 431). Span 60 is recommended by in some scientific articles for vaginal use in concentrations of 3-10\% (much higher values compared to a maximum of $2 \%$ for sodium laurylsulphate), having a lower local irritant effect, and a stronger foaming effect $[11,17,24]$.

To compare the foaming effect of Span60 the N8 formulation was chosen and tablets were prepared in similar condition, but replacing the sodium laurylsulphate with Span60, in the same concentration. Formulation N8 contains $1.5 \%$ sodium laurylsulphate, and at this concentration may be irritant for the vaginal mucosa. Replacing with Span60 could reduce the irritating effect and improve the foaming effect is expected. The N8 formulation was

TABLE 6. The results obtained on $\mathrm{N} 15$ formulation stored in different environmental conditions

\begin{tabular}{|c|c|c|c|c|c|c|c|c|}
\hline & $\begin{array}{c}\text { Tablets } \\
\text { hardness }\end{array}$ & $\begin{array}{l}\text { Foaming } \\
\text { time' } \\
\text { (min) }\end{array}$ & $\begin{array}{l}\text { Maximum } \\
\text { volume of the } \\
\text { foam } \\
\text { (ml) }\end{array}$ & $\begin{array}{l}\text { Resistance } \\
\text { of the foam } \\
\text { (min) }\end{array}$ & $\begin{array}{c}\text { Mass of CO2 } \\
\text { released } \\
\text { (g) }\end{array}$ & $\begin{array}{l}\text { pH generated } \\
\text { in wate }\end{array}$ & $\begin{array}{c}\mathrm{pH} \\
\text { generated } \\
\text { in SVF }\end{array}$ & $\begin{array}{c}\text { Difference } \\
\text { in humidity } \\
(\%)\end{array}$ \\
\hline $\begin{array}{c}\text { After } \\
\text { preparation } \\
\text { storage in } \\
\text { NTH } \\
\end{array}$ & 10 & 4.9 & $14.5 \mathrm{ml}$ & 15 & 0.275 & 5.28 & 4.72 & 1.34 \\
\hline $\begin{array}{c}\text { After } \\
\text { preparation } \\
\text { storage in } \\
\text { LTH } \\
\end{array}$ & 10 & 4.9 & $14.5 \mathrm{ml}$ & 15 & 0.275 & 5.28 & 4.72 & 1.34 \\
\hline $\begin{array}{l}1 \text { month } \\
\text { storage } \\
\text { in NTH }\end{array}$ & 13.5 & 7.4 & $11.5 \mathrm{ml}$ & 23 & 0.212 & 5.32 & 4.55 & +0.58 \\
\hline $\begin{array}{c}1 \text { month } \\
\text { storage in } \\
\text { LTH }\end{array}$ & 10.5 & 5.5 & $13 \mathrm{ml}$ & 24 & 0.255 & 5.30 & 4.69 & -0.11 \\
\hline $\begin{array}{l}3 \text { months } \\
\text { storage in } \\
\text { NTH }\end{array}$ & 14 & 13.3 & $11 \mathrm{ml}$ & 23.5 & 0.191 & 5.51 & - & +0.89 \\
\hline $\begin{array}{c}3 \text { months } \\
\text { storage in } \\
\text { LTH }\end{array}$ & 12 & 7 & $13.5 \mathrm{ml}$ & 23 & 0.214 & 5.45 & - & +0.21 \\
\hline
\end{tabular}

$\mathrm{NTH}$ - normal thermo-hygrometric conditions (temperature of $25^{\circ} \mathrm{C}$, relative humidity $40-75 \%$ ), in tightly sealed bottles with anhydrous sodium sulphate as desiccant

$\mathrm{LTH}$ - low hygrometric conditions (temperature of $25^{\circ} \mathrm{C}$, relative humidity below $10 \%$ provided anhydrous calcium chloride in a desiccator) 
chosen because generated a foam volume of $12 \mathrm{ml}$, with a mechanical resistance of 20 minutes (very good values); but the main reason for choosing this formulation was the high stability over time, the values obtaining after one and three months storage were very close to those obtained immediately after preparation. The obtained results on $\mathrm{N} 8$ formulation with $1.5 \%$ Span 60 are presented in table 7.

The obtained results show large differences between the two formulations, in terms of foaming time, maximum volume foam and resistance of the foam; and small differences for the other parameters studied.

By replacing the foaming agent sodium laurylsulphate with Span60, the tablets have the same stability over time, but with a much higher foaming capacity, giving match higher maximum volume of the foam associated with a much higher mechanical resistance of the foam, this effect is associated with faster disaggregation and decrease the foaming time. Thus, a halving of the foaming time, a doubling of the foam volume and an increase almost 6 times of the mechanical resistance of the foam was obtained. The other parameters studied and the stability over time not undergoing a change as those related to effervescence and foaming process. So, the replacement of sodium laurylsulphate with Span60 has a beneficial effect on the disintegrating and foaming properties of the tablets, with the possibility of reducing the concentration of Span60 foaming agent in order to obtain an effect similar to that obtained for a higher concentration sodium laurylsulphate. This replacement could also reduce the local irritating effect $[11,24]$.

\section{CONCLUSIONS}

The stability of foaming vaginal tablets over time after storage under normal environmental thermohygrometric conditions was evaluated. It can be observed that after 1 or 3 months storage, the studied formulation factors have, in general, the same influence on the tablets characteristics as immediate after preparation.

The results obtained after one month storage in normal thermo-hygrometric conditions, in the presence of anhydrous sodium sulphate (as desiccant), show increase of the tablets hardness and the foaming time, decrease of the volume of the foam, the mass of carbon dioxide released by the foaming, which can be translated into decrease of the tablets stability over time. This instability over time is accentuated especially with an increased effervescent mixture ratio and not significantly influenced by the other formulation variables. An interesting result is the

TABLE 7. The results obtained on N8 formulation with 1.5\% Span60

\begin{tabular}{|c|c|c|c|c|c|c|c|c|c|}
\hline & & $\begin{array}{c}\text { Tablets } \\
\text { hardness }\end{array}$ & $\begin{array}{c}\text { Foaming } \\
\text { time' } \\
\text { (min) }\end{array}$ & $\begin{array}{l}\text { Maximum } \\
\text { volume of } \\
\text { the foam } \\
(\mathrm{ml})\end{array}$ & $\begin{array}{l}\text { Resistance of } \\
\text { the foam } \\
\text { (min) }\end{array}$ & $\begin{array}{c}\text { Mass } \\
\text { of CO2 } \\
\text { released } \\
\text { (g) }\end{array}$ & $\begin{array}{c}\mathrm{pH} \\
\text { generated } \\
\text { in wate }\end{array}$ & $\begin{array}{c}\mathrm{pH} \\
\text { generated } \\
\text { in SVF }\end{array}$ & $\begin{array}{c}\text { Difference } \\
\text { in humidity } \\
(\%)\end{array}$ \\
\hline \multirow{2}{*}{$\begin{array}{l}\text { Immedi- } \\
\text { ate after } \\
\text { prepara- } \\
\text { tion }\end{array}$} & $\begin{array}{c}\text { Formulation } \\
\text { N8 } \\
\text { with LSNa }\end{array}$ & 5.5 & 7.5 & 12.0 & 20 & 0.28 & 4.85 & 4.49 & 1.15 \\
\hline & $\begin{array}{l}\text { Formulation } \\
\text { N8 } \\
\text { with Span60 }\end{array}$ & 5.0 & 4.0 & 24.5 & 115 & 0.27 & 4.5 & 4.37 & 1.17 \\
\hline \multirow{2}{*}{$\begin{array}{l}\text { After } 1 \\
\text { month } \\
\text { storage }\end{array}$} & $\begin{array}{l}\text { Formulation } \\
\text { N8 with LSNa }\end{array}$ & 12.5 & 9.5 & 11.5 & 30 & 0.20 & 4.56 & 4.49 & +0.61 \\
\hline & $\begin{array}{c}\text { Formulation } \\
\text { N8 with } \\
\text { Span60 }\end{array}$ & 11.0 & 6.0 & 22.0 & 130 & 0.19 & 4.32 & 4.35 & +0.65 \\
\hline \multirow{2}{*}{$\begin{array}{l}\text { After } 3 \\
\text { months } \\
\text { storage }\end{array}$} & $\begin{array}{l}\text { formulation } \\
\text { N8 with LSNa }\end{array}$ & 12.5 & 11 & 11.0 & 28 & 0.18 & 4.27 & - & +1.1 \\
\hline & $\begin{array}{l}\text { Formulation } \\
\text { N8 with } \\
\text { Span60 }\end{array}$ & 11.0 & 7.5 & 21.5 & 135 & 0.18 & 4.22 & - & +1.02 \\
\hline
\end{tabular}


increase of the resistance of the foam obtained by disintegrating the tablets after one month of storage, compared to the foam resulting from the tablets immediate after preparation. In terms of $\mathrm{pH}$, this parameter does not vary much over time, and depends on the same factors as after preparation, the largest influence having in this case the citric acid excess in the formulation. Regarding the tablets hardness after a month of storage it can be observed an increase dependent on the effervescent mixture ratio.

The results obtained after three months storage in normal thermo-hygrometric conditions, show that the changes on the tablets characteristics become slower than in the first month. The tablets hardness reaches maximum values after one month, but also there are slower changes regarding the maximum volume of the foam, the resistance of the foam, or the mass of carbon dioxide released after foaming. An exception is the foaming time for which an increase over time was observed. Another parameter with low modification is the $\mathrm{pH}$ in the water, which has a fairly high stability over time, both at one month and after three months of storage.

The formulations with a lower effervescent mixture ratio (less than $25 \%$ ), storage conditions may allow constant humidity or even lower humidity, but at higher percentages of effervescent mixture, the formulation is the main factor that intervenes in the increase of humidity over time.

The final conclusion is that the tablets stored in normal thermo-hygrometric conditions, suffer a sudden modification of their characteristics during the first month of storage, a phenomenon that is due to both the humidity of the environment and the preparation conditions. This modification can be minimized by preparing and storing tablets in low humidity conditions (lower that $10 \%$ ) or by preparation the formulations with a lower effervescent mixture ratio (less than 25\%).

Conflict of interest: none declared Financial support: none declared

\section{REFERENCES}

1. Maggi L, Mastromarino P, Macchia S, Brigidi P, Pirovano F, Matteuzzi D, Conte U. Technological and biological evaluation of tablets containing different strains of lactobacilli for vaginal administration. Eur. J.Pharm. Biopharm. 2000; 50:389-395.

2. Bhat SR, Shivakumar HG. Bioadhesive Controlled Release Clotrimazole Vaginal Tablets Trop J Pharm Res, August 2010; 9 (4): 339-346.

3. Parrott EL. Formulation of a foaming vaginal tablet and suppository. Drug Development and Industrial Pharmacy 1988;14(8):1013-1021.

4. Gavini E, Sanna V, Juliano C, Bonferoni MC, Giunchedi P. Mucoadhesive vaginal tablets as veterinary delivery system for the controlled release of an antimicrobial drug, acriflavine. AAPS PharmSciTech. 2002;3(3):E20.

5. Pather SI, Khankari RK, Eichman JD, Robinson JR, Hontz J. Sublingual buccal effervescent. United States Patent, 6200604, June 8, 1999.

6. Eichman JD, Robinson JR. Mechanistic studies on effervescent induced permeability enhancement. Pharmaceutical Research, 1998;15(6):925-930.

7. Karasulu HY, Taneri F, Sanal E, Guneri T, Ertan G. Sustained release bioadhesive effervescent ketoconazole microcapsules tabletted for vaginal delivery. Microencapsulation, 2002;19(3):357-362.

8. Bansal S, Beg S, Garg B, Asthana A, Asthana GS, Singh B. QbDOriented Development and Characterization of Effervescent Floating-Bioadhesive Tablets of Cefuroxime Axetil. AAPS PharmSciTech. 2016;17(5):1086-99.

9. Aslani A, Sharifian T. Formulation, characterization and physicochemical evaluation of amoxicillin effervescent tablets. Adv Biomed Res. 2014;3:209.

10. Aslani A, Jahangiri H. Formulation, characterization and physicochemical evaluation of ranitidine effervescent tablets. Adv Pharm Bull. 2013;3(2):315-22.
11. Aulton ME. Pharmaceutics: The science of dosage form design. Chuchill Livingstone, London, 2002.

12. Garg S, Tambwekar KR, Vermani K, Garg A, Kaul CL, Zaneveld LJD Compendium of Pharmaceutical Excipients for Vaginal Formulations; Pharmaceutical Technology 2001;25(9):14-24.

13. László E, Tomuta I, Leucuta SE. Development of foaming vaginal tablets with clotrimazole. Part I. Optimization of the formulation using design of experiments approach. Ro J Pharm Pract. 2020;13(2):66-78.

14. European Pharmacopoeia 10th Edition. Strasbourg: Council of Europe, 2020. Online edition https://pheur.edqm.eu/home.

15. Yanze MF, Duru C, Jacob M, Gasc F. The carbon dioximeter: a device for quantifying the carbon dioxide released from effervescent pharmaceuticals. J Pharm Belg. 2000;55(2):53-6.

16. Anderson NR, Banker GS, Peck GE. Quantitative evaluation of pharmaceutical effervescent systems I: Design of testing apparatus. J Pharm Sci. 1982;71(1):3-6.

17. Faguetet JP, Spingler $E$, Duchène $D$, Puisieux F. Comprimés. XIV. Etude de l'influence de l'humidité et de la température sur la conservation de comprimés effervescents; Pharm Acta Helv. 1975;50(9):251-261.

18. Muntean AC, Negoi OI, Rus LL, Vonica AL, Tomuţă I. Formulation of orodispersible tablets containing paracetamol and their in vitro characterization - a QbD approach. Farmacia 2020;(68):3:436-446.

19. Iurian S, Ilie L, Achim M, Tomuță I. The evaluation of dynamic compaction analysis as a qbd tool for paediatric orodispersible minitablet formulation. Farmacia 2020;68 (6):999-1010.

20. Eriksson L, Johansson E, Kettaneh-Wold N, WikstromC, Design of experiments, principles and applications,3rdedition, Umetrics Academy, Umea, 2008. 
21. Zanze FM, Duru C, Jacob M. A Process to Produce Effervescent Tablets: Fluidized Bed Dryer Melt Granulation; Drug Dev Ind Pharm. 2002;26(11):1167-1176.

22. Chowhan ZT. The effect of low- and high-humidity ageing on the hardness, disintegration time and dissolution rate of dibasic calcium phosphate-based tablets. J Pharm Pharmacol. 1980;32(1):10-14.
23. Schaeffer A EE. Effervescent pharmaceutical compositions. United States Patent 5468504, November 21,1995.

24. Sheskey PJ, Hancock BC, Moss GP, Goldfarb DJ. Handbook of Pharmaceutical Excipients. 9th Edition, Pharmaceutical Press, London 2020. 